\title{
Compliance with Environmental Safeguard Policy - Comparative Analysis of Projects Financed by Asian Development Bank
}

\author{
Masami Tsuji
}

\begin{abstract}
To identify common issues on environmental safeguard in infrastructure projects, a comparative analysis was undertaken for five projects which were financed by Asian Development Bank (ADB) and subject to environmental compliance review. Various elements were identified for successfully carrying out projects without causing environmental problems. Among those, the following were found in most of the studied projects and thus considered crucial: collecting baseline data, ensuring proper coverage of environmental assessment, appropriately assessing adverse impacts, and sufficiently carrying out public consultation and information disclosure. Whereas it is not widely noticed, changes in project scope sometimes occur and they trigger additional actions for safeguard compliance. In the recently established Environmental and Social Policy, the World Bank and Asian Infrastructure Investment Bank (AIIB) introduced a new concept of "adaptive management." Intensive attention should be paid to proper implementation of this aspect.
\end{abstract}

Index Terms-Adaptive management, Asian Development Bank, changes in project scope, compliance review, environmental safeguard.

\section{INTRODUCTION}

International financing institutions (IFIs) provide developing countries with projects for basic infrastructure development, such as roads, power plants, water supply facilities. Whereas such projects are intended to make life of the people better, those sometimes adversely affect people living in or around the project site. To avoid or minimize adverse impacts, and enhance or at least restore their livelihoods, IFIs establish, implement, and update "safeguard policy," which stipulates compliance requirements on environmental and social issues during project preparation, implementation and operation. However, there still are a few projects that have environmental and/or social issues because of insufficient preparation or implementation on safeguards.

In August 2016, the World Bank established its new safeguard policy as Environmental and Social Framework, which is expected to be in use after a preparation and training period of 12 to 18 months [1]. In February 2016, Asian Infrastructure Investment Bank (AIIB) also established Environmental and Social Framework, which is already in effect (as there is no preceding policy) [2]. Independent Evaluation's review of Asian Development Bank (ADB), on how ADB applied its 2010-launched Safeguard Policy

Manuscript received July 21, 2017; revised September 23, 2017.

Masami Tsuji is with Japan International Cooperation Agency (JICA), Tokyo, Japan (e-mail: Tsuji.Masami@jica.go.jp).
Statement, was published in December 2014 [3].

In this study, a comparative analysis was carried out on issues of development projects that have become subject to ADB's compliance review, to identify common issues that hindered projects from safeguard policy compliance. It clarifies on which points policy implementation should be improved. This kind of comparative analysis on compliance review cases has not been done before, except for those by the Inspection Panel of the World Bank (on involuntary resettlement, indigenous peoples, and environment) [4]-[6], and the author and Fujikura (on involuntary resettlement for ADB projects) [7]. The former classified major issues including: screening and scoping; impact identification and assessment; consultation; and monitoring and supervision. The latter identified crucial elements for resettlement such as: timely establishment of a resettlement plan based on sufficient survey and consultation; revision of the plan when necessary; clear understanding of the plan by all stakeholders; and engagement of a capable monitoring institution.

Safeguard policies cover both environmental and social aspects. This study focused on environmental aspects.

\section{METHODS AND MATERIALS}

\section{A. Methods}

Most of the IFIs have a mechanism that enables affected people to directly complain to IFIs on compliance issues with safeguard policies. Such mechanism is usually a small unit, independent of project operations departments (where project teams exist), reporting directly to the Board or the President, depending on IFIs. It handles two phases for complaints: consultation phase and compliance review phase. This study focused on the latter as cases that have elements difficult to solve.

Once the mechanism has received a request for compliance review, eligibility of the request is discussed. If the request is judged as eligible, the mechanism carries out document review, site visit, and meetings with IFI staff, borrower, requesters, etc. Then it prepares a draft report with recommendations for the IFI. The draft report is usually reviewed by the IFI management and the requesters, and their comments are attached to the final report that is submitted to the Board of the IFI, and disclosed to the public (Fig. 1).

Since such mechanism is to find compliance or non-compliance of the IFI with its own policy, it does not directly review compliance of the borrower/client. If there are concerns on actions done by the borrower/client, the 
mechanism will review whether supervision of the IFI was compliant or not. If requesters would like to take actions directly against the borrower/client, they can use legal system of the country (such as lawsuit) independently of the IFI's mechanism. In the case of ADB, the mechanism is played by Compliance Review Panel (CRP).

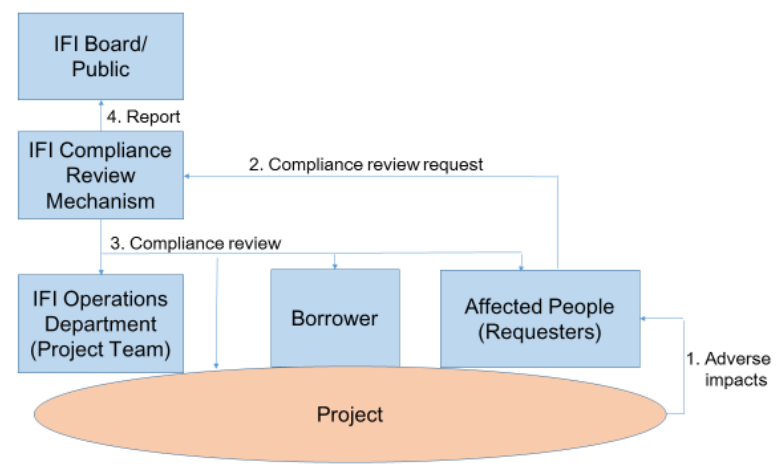

Fig. 1. IFI compliance review mechanism and projects. (Source: Author, based on information of IFIs)

\section{B. Materials}

There are 9 ADB projects that were subject to compliance review and had the final review report as of 20 July 2017. Out of those, there are 5 projects that had environmental aspects in noncompliant elements [8]-[12]. This study discusses all of these 5 projects (Table I). In most cases, there are different views among CRP, requester, and IFI management. Since this study does not aim at identifying which view is correct, it adopted the view of CRP for discussion. The view of CRP is considered most objective, and using the view of only one of those three players makes the basis of discussion consistent.

TABLE I: LIST OF PROJECTS STUDIED

\begin{tabular}{|l|l|l|}
\hline No. & country & project name \\
\hline 1 & Pakistan & $\begin{array}{l}\text { Chashma Right Bank Irrigation Project (Phase III) } \\
\text { [hereinafter, "Chashma"] }\end{array}$ \\
\hline 2 & Sri Lanka & Southern Transport Development Project [STDP] \\
\hline 3 & Philippines & $\begin{array}{l}\text { Visayas Base-Load Power Development Project } \\
\text { [Visayas] }\end{array}$ \\
\hline 4 & India & Mundra Ultra Mega Power Project [Mundra] \\
\hline 5 & Georgia & $\begin{array}{l}\text { Sustainable Urban Transport Investment Program } \\
\text { (Tranche 3) [SUTIP] }\end{array}$ \\
\hline
\end{tabular}

\section{RESULTS}

Table II is a summary of environmental safeguard issues observed in the projects. In order to make clear what actual issues are, itemization of issues was done by the author rather than following itemization of policy requirements.

\begin{tabular}{|c|c|c|c|c|c|}
\hline project & 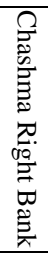 & 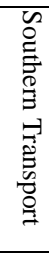 & 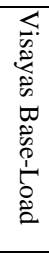 & 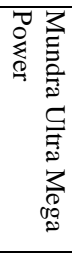 & 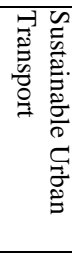 \\
\hline $\begin{array}{l}\text { A. Environment } \\
\text { Category }\end{array}$ & $\mathrm{x}$ & & & & $\mathrm{x}$ \\
\hline $\begin{array}{l}\text { B. Baseline data } \\
\text { collection }\end{array}$ & $\mathrm{x}$ & & $\mathrm{x}$ & $\mathrm{x}$ & $\mathrm{X}$ \\
\hline
\end{tabular}

\begin{tabular}{|c|c|c|c|c|c|}
\hline $\begin{array}{l}\text { C. Examination of } \\
\text { alternatives }\end{array}$ & & $\mathrm{x}$ & $\mathrm{X}$ & & \\
\hline $\begin{array}{l}\text { D. Coverage of } \\
\text { environmental } \\
\text { assessment / due } \\
\text { diligence }\end{array}$ & & $\mathrm{X}$ & $\mathrm{X}$ & $\mathrm{x}$ & $\mathrm{x}$ \\
\hline $\begin{array}{l}\text { E. Timely preparation of } \\
\text { environmental } \\
\text { assessment }\end{array}$ & $\mathrm{X}$ & & & & \\
\hline $\begin{array}{l}\text { F. Assessment quality of } \\
\text { adverse impacts }\end{array}$ & $\mathrm{X}$ & $\mathrm{x}$ & $\mathrm{X}$ & $\mathrm{x}$ & $\mathrm{x}$ \\
\hline $\begin{array}{l}\text { G. Compliance with } \\
\text { international standards }\end{array}$ & & & $\mathrm{X}$ & $\mathrm{X}$ & $\mathrm{x}$ \\
\hline $\begin{array}{l}\text { H. Update or amendment } \\
\text { of environmental } \\
\text { assessment }\end{array}$ & & $\mathrm{X}$ & $\mathrm{X}$ & & \\
\hline $\begin{array}{l}\text { I. Preparation of } \\
\text { appropriate EMP }\end{array}$ & $\mathrm{X}$ & & $\mathrm{x}$ & & \\
\hline $\begin{array}{l}\text { J. Public consultation and } \\
\text { information disclosure }\end{array}$ & $\mathrm{X}$ & $\mathrm{X}$ & $\mathrm{X}$ & $\mathrm{x}$ & $\mathrm{x}$ \\
\hline $\begin{array}{l}\text { K. Implementation of } \\
\text { mitigation measures }\end{array}$ & $x$ & & & & \\
\hline $\begin{array}{l}\text { L. Changes in project } \\
\text { scope }\end{array}$ & $\mathrm{X}$ & $\mathrm{X}$ & & $\mathrm{x}$ & $\mathrm{x}$ \\
\hline
\end{tabular}

(Source: Author, based on information of [8]-[12])

Note: No tick means either: (i) it is not an issue for the project, or (ii) no information is available on that issue.

\section{A. Environment Category (2 Cases)}

At project screening stage, environment category for a project is determined by the project team of ADB. Chashma was classified to Environment Category B that needs an initial environmental examination (IEE) only. As a large-scale irrigation project and possible magnitude of environmental impacts, it should have been classified to a different category that needs a full environmental impact assessment (EIA) [8]. SUTIP was also classified to Environment Category B. The road passes through densely populated areas, and will create noise and vibration impacts. Its highway section includes a new road to be constructed along and into a river that is an international waterway. A reclassification to the higher category that requires EIA preparation should have been considered [12].

\section{B. Baseline Data Collection (4 Cases)}

Baseline data collection is important for assessing impacts of the project and determining mitigation measures. By nature, it is not possible to collect such data once the project implementation has started. The lack of information that caused constraints for assessing environmental impacts of Chashma relates to baseline data on a number of fundamental environmental indicators [8]. For Visayas, sampling procedure for ambient air quality data was not appropriate [10]. For Mundra, time series of fishing data along the coast was not collected and caused difficulties for impact assessment [11]. Baseline data on ecological resources of the 
river that will be affected by SUTIP were not collected, and assessment was not carried out. In that project, the vibration study did not measure natural frequencies in the affected residential buildings [12].

\section{Examination of Alternatives (2 Cases)}

Analysis of alternatives is a major part of environmental assessment. Road realignments in STDP made opportunities to re-examine alternatives and it is not clear that all the parties involved wanted to re-open a discussion on alternatives [9]. The EIA report for Visayas did not contain systematic and rigorous analysis of alternatives. Discussions on alternatives in project documents varied regarding plant locations, fuel types, and boiler technologies [10].

\section{Coverage of Environmental Assessment / Due Diligence (4 Cases)}

Environmental assessment and its due diligence should cover all major elements of project specific environmental issues. For STDP, risk of landslides should have been assessed. The EIA for STDP did not assess an access road component [9]. For Visayas, rigorous due diligence on ash management plan was not done. Also, its EIA did not address potential impacts of historic ash disposal [10]. Mundra failed to identify seasonal fisherfolk as project-affected people. Thus no baseline and monitoring data were collected, impacts were not identified, and mitigation measures were not considered [11]. For SUTIP, impact assessment on vulnerable groups, vibration, water and river ecology, and light was limited [12].

\section{E. Timely Preparation of Environmental Assessment (1 Case)}

Environmental assessment should be carried out at an early stage of project preparation so that its findings and recommendations can be reflected to the project design and implementation. For Chashma, the environmental assessment report was not produced prior to appraisal and approval of the project, which is a noncompliance with the operations manual on environmental consideration [8].

\section{F. Assessment Quality for Adverse Impacts (All 5 Cases)}

Appropriate environmental assessment of good quality is the basis for safeguards. For Chashma, assessment of: (i) flooding, (ii) agricultural chemicals, (iii) forests and grazing lands, (iv) water-logging and salinization, and (v) pollution and waste management in agro-industries was not appropriate [8]. The EIA for STDP was weak in assessing natural resources and ecology, inland fisheries and aquaculture, wetlands, health issues, and possible induced developments [9]. For Visayas, the environmental assessment summarized the air dispersion modeling and associated findings without considering the validity of the data from the existing power plant and other emission sources, or compliance with international ambient air quality criteria [10]. In Mundra, assessment of ambient air quality and access restrictions to fishing grounds [11] was not appropriate. For SUTIP, impact assessment on noise and vibration was not appropriate [12].

\section{G. Compliance with International Standards (3 Cases)}

For ADB projects, application of good international practice in addition to compliance with national standards is required. In Visayas project, baseline air quality data were generated using the 1-hour sampling period while 24-hour sampling period was required as international practice [10]. In Mundra, guidelines in Pollution Prevention and Abatement Handbook of the World Bank were not followed in terms of temperature rise of cooling water discharge, dilution of discharged chemicals, and air quality [11]. As noise standards, SUTIP should have used the World Bank Group's Environment, Health and Safety Guidelines that are more stringent than national standards [12].

\section{H. Update or Amendment of Environmental Assessment (2 Cases)}

Whereas not all projects need update or amendment of environmental assessment, there are cases that need such actions. For STDP, no updates or amendments were made to the environmental assessment report after the Central Environmental Authority (CEA) of Sri Lanka gave conditional approval that lead to changes in road alignments [9]. For Visayas, before ADB got involved, the EIA report was prepared to comply with national requirements. But it was not updated to meet ADB requirements [10].

\section{Preparation of Appropriate EMP (2 Cases)}

Implementation of mitigation measures and other actions prescribed in the environmental assessment is materialized through implementation of an environmental management plan (EMP) that is prepared as part of environmental assessment. For Chashma, an EMP was prepared in 1995 while project approval was in 1991. Its implementation did not commence until 2004 [8]. On Visayas, the EMP in the EIA did not address ambient air quality monitoring requirements or managing and disposing of the ash generated by the power plant [10].

\section{J. Public Consultation and Information Disclosure (All 5 Cases)}

Public consultation and information disclosure are central aspects to achieve objectives of safeguards. For Chasma, no opportunities for participation between 1997 and 2001 were referred to, except for the initial phase of resettlement planning. Even in 2004, there still were difficulties for the voice of affected people to be heard [8]. Whereas two hearings for STDP were held, those did not give sufficient opportunity for all the affected people [9]. In Visayas, the significance of health concerns raised during consultations was not well-recognized [10]. For Mundra, there is no evidence that the second round consultation with affected people was carried out [11]. In SUTIP, the consultation did not adequately incorporate views of vision impaired persons and other vulnerable people. There were no special outreach efforts for them [12].

\section{K. Implementation of Mitigation Measures (1 Case)}

If mitigation measures are not implemented, there is no meaning of preparing an environmental assessment report and EMP. Chashma did not have budget items for mitigation measures, and thus responsibility of implementing the EMP was transferred to a different project [8]. 


\section{Changes in Project Scope (4 Cases)}

Changes in project scope occur in some projects even at project implementation stage. They trigger additional actions for safeguard compliance. Chashma had discussions on options of resettlement or flood protection even during project implementation [8]. STDP made changes in road alignments based on conditions given from CEA, which needed additional EIA and social assessment during project implementation [9]. Mundra had a new location of its outfall channel for cooling water discharge, which generated additional project-affected people [11]. For SUTIP, a highway was originally planned with a revetment along the river, which was changed to build a retaining wall into the river [12].

\section{DISCUSSIONS AND CONCLUSIONS}

Elements listed in Table II were identified as challenges on environmental safeguard compliance. Among those, the following were found in most of the projects studied and thus considered crucial: collecting baseline data; ensuring proper coverage of environmental assessment; appropriately assessing adverse impacts; and sufficiently carrying out public consultation and information disclosure. Those are basic elements of environmental compliance but still have difficulties for proper implementation.

Whereas it is not widely noticed, changes in project scope sometimes occur and they trigger additional actions for safeguard compliance. The author and and Fujikura pointed out this aspect in involuntary resettlement [7]. This study found a similar situation also in environmental safeguard cases.

In the reports of the World Bank's Inspection Panel, only the volume on Indigenous Peoples refers to this aspect [5]. In the recently established Environmental and Social Policy, the World Bank and AIIB respectively introduced a new concept of "adaptive management," to be responsive to project changes or unforeseen circumstances [1], [2]. This concept is new for both institutions. On the other hand, in ADB, the current safeguard policy statement has arrangements for changes in project design or unforeseen events [13]. Whereas the term "adaptive management" is not used, the arrangements in ADB policy are to respond to similar situations. This means that the existence of policy requirements on specific issue does not automatically solve the issue, but timely and proper implementation and/or supervision followed by actions are required. Strengthening of capacity in both IFIs and borrowers/clients to monitor project implementation and take corrective actions will be the key for the success.

\section{REFERENCES}

[1] World Bank, "Environmental and social framework," August 2016.

[2] Asian Infrastructure Investment Bank, "Environmental and social framework," February 2016.

[3] Asian Development Bank (ADB), "Learning lessons: ADB's safeguard policy".

[4] World Bank, "Involuntary resettlement (emerging lessons series No. 1)," The Inspection Panel, April 2016.

[5] The Inspection Panel, "Indigenous peoples (emerging lessons series No. 2)," October 2016.

[6] The Inspection Panel, "Environmental assessment (emerging lessons series No. 3)," April 2017.

[7] M. Tsuji and R. Fujikura, "Issues of implementing involuntary resettlement policy of Asian Development Bank - Case studies of projects subject to compliance review," Public Policy and Social Governance, pp. 117-134, 2016.

[8] ADB, "Appendix 6: Final report of inspection panel" of "Report and Recommendation of the Board Inspection Committee to the Board of Directors on the Request for Inspection on Chashma Right Bank Irrigation Project (Stage III) (ADB Loan No. 1146-PAK [SF]) in the Islamic Republic of Pakistan," July 2004.

[9] Final Report to the Board of Directors on CRP Request No. 2004/1 on the Southern Transport Development Project in Sri Lanka (ADB Loan No. 1711-SRI [SF]), June 2005.

[10] Final Report on Compliance Review Panel Request No. 2011/1 on the Visayas Base-Load Power Development Project in the Republic of the Philippines (ADB Loan No. 2612-PHI), 2012

[11] Final Report on Compliance Review Panel Request No. 2013/1 on the Mundra Ultra Mega Power Project in India (Asian Development Bank Loan 2419), March 2014.

[12] Final Report on Compliance Review Panel Request No. 2016/1 on the Sustainable Urban Transport Investment Program (Tranche 3) in Georgia (Asian Development Bank Loan 3063), February 2017.

[13] Safeguard Policy Statement, June 2009

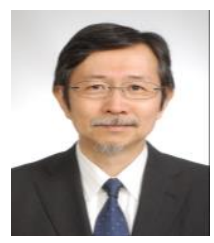

Masami Tsuji was born in 1960. He graduated from Faculty of Science, University of Tokyo in 1984, and obtained the Ph.D. degree from Hosei University in 2017. His field of work is environmental policy formulation and implementation. He worked for the government of Japan in the Ministry of Environment, the Ministry of Health and Welfare, and Overseas Economic Cooperation Fund, and for Asian Development Bank. He is currently senior advisor (environmental management) for Japan International Cooperation Agency (JICA). 